\title{
Interference of $50 \mathrm{~Hz}$ electrical cortical potentials evoked by TV systems
}

\author{
G. H. M. van Lith, G. W. van MARLE, and S. VIJfVINKEL-BRUINENGA \\ From the Eye Department, Erasmus University, Eye Hospital, Rotterdam, The Netherlands
}

SUMMARY Application of TV systems for generating patterned stimuli for the examination of the electrical cortical potentials has disadvantages caused by the frame frequency of $50 \mathrm{~Hz}$ of TV sets. Apart from a larger variability in latency times of the electrical potentials as compared to the results obtained by projector systems, a $50-\mathrm{Hz}$ noise on the recordings mediated through the visual system may be seen. These disadvantages can be ameliorated by increasing the frame frequency of the TV set.

In a previous paper (van Lith et al., 1978) some disadvantages of the application of television (TV) systems as a stimulus device for evoking electrical cortical potentials (EPs) were discussed. We paid attention mainly to the variability in latency times due to the frame frequency of the TV. Another disadvantage, namely, a $50 \mathrm{~Hz}$ interference in the recordings, was mentioned as being present only when the starting points of the visual stimuli were synchronised with frame of the TV screen. The cause of this $50 \mathrm{~Hz}$ noise was not discussed because we thought it originated in induction, but the cause of it has since turned out to be different.

\section{Materials and methods}

A TV stimulus device, similar except in inessential details to Arden's (Arden and Faulkner, 1977), was applied. Synchronisation of stimulus and frame caused a $50 \mathrm{~Hz}$ ripple, which particularly hampered the measurement of small potentials (Fig. 1). Tests to diminish this ripple were carried out with a blank TV screen, without a luminance or patterned stimulus. The field size of the TV screen was approximately $26^{\circ}$. Electrode positions were the same as in the previous paper. The band width of the amplifiers was $0 \cdot 1$ to $100 \mathrm{~Hz}$, and 128 counts were averaged. The $50 \mathrm{~Hz}$ noise was investigated further (Figs. 2 and 3) with a band filter of $50 \mathrm{~Hz}$. Experiments were carried out on persons whose recordings always showed much of this $50 \mathrm{~Hz}$ noise.

Correspondence to Dr G. H. M. van Lith, Eye Department, Erasmus University, Eye Hospital, Schiedamse Vest 180, 3000 LM Rotterdam, The Netherlands
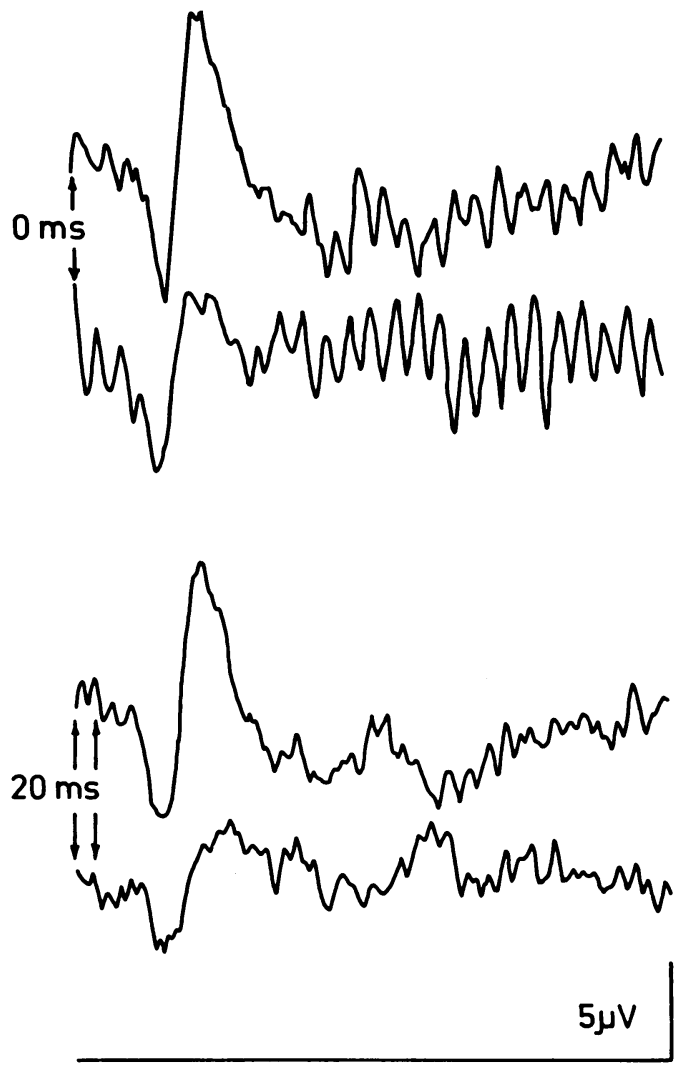

$500 \mathrm{~ms}$

Fig. 1 EPs to a $1-\mathrm{Hz}$ pattern flash stimulus of $40 \mathrm{~ms}$ duration. (A) synchronisation between the frame frequency of the TV set and the pattern generator; (B) no synchronisation, i.e., the stimulus starts at random within $20 \mathrm{~ms}$. The upper recordings of each pair are from bipolar leads over the occipital lobe, the lower ones are made in reference to the ear lobe 


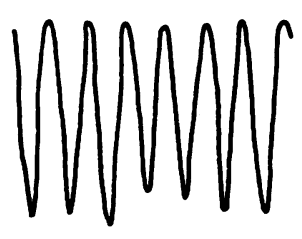

A
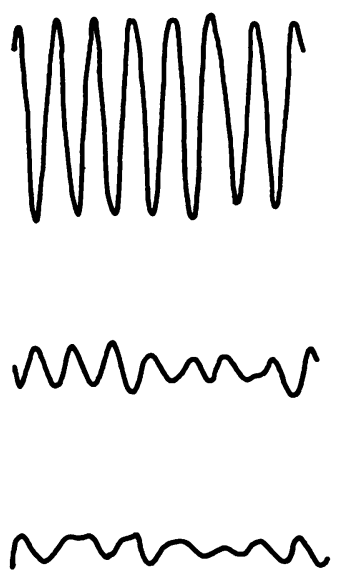

D
B

Fig. $250-\mathrm{Hz}$

potentials of

approximately $4 \mu \mathrm{V}$, registered from the occipital lobe and provoked by a blank $T V$ screen, synchronised with the averager. (A) un-

C shielded; (B)

electrically shielded; (C) visually shielded; (D) visually and electrically shielded

\section{Discussion}

We believe the 2 factors responsible for the variable latency times (van Lith et al., 1978) also cause the visual hum. These 2 factors were the sequential lighting up of the TV screen every $20 \mathrm{~ms}$ and the small EP visual field - that is, the part of the visual field from which the EPs are mediated.

The picture on a TV screen is built up by a light point which runs over the screen in $20 \mathrm{~ms}$. When the light point is outside the EP visual field, the screen is dark for the electrode which records the evoked potential. When the light point runs inside the EP visual field, the screen lights up in relation to the electrode placed over the visual cortex. This implies that every $20 \mathrm{~ms}$, that is, 50 times per second, the electrode over the cortex sees a light stimulus and registers an evoked potential, at least if the $50 \mathrm{~Hz}$ flicker is below the critical fusion frequency (CFF) of the visually evoked cortical potentials.

Data about the latter can be obtained from a
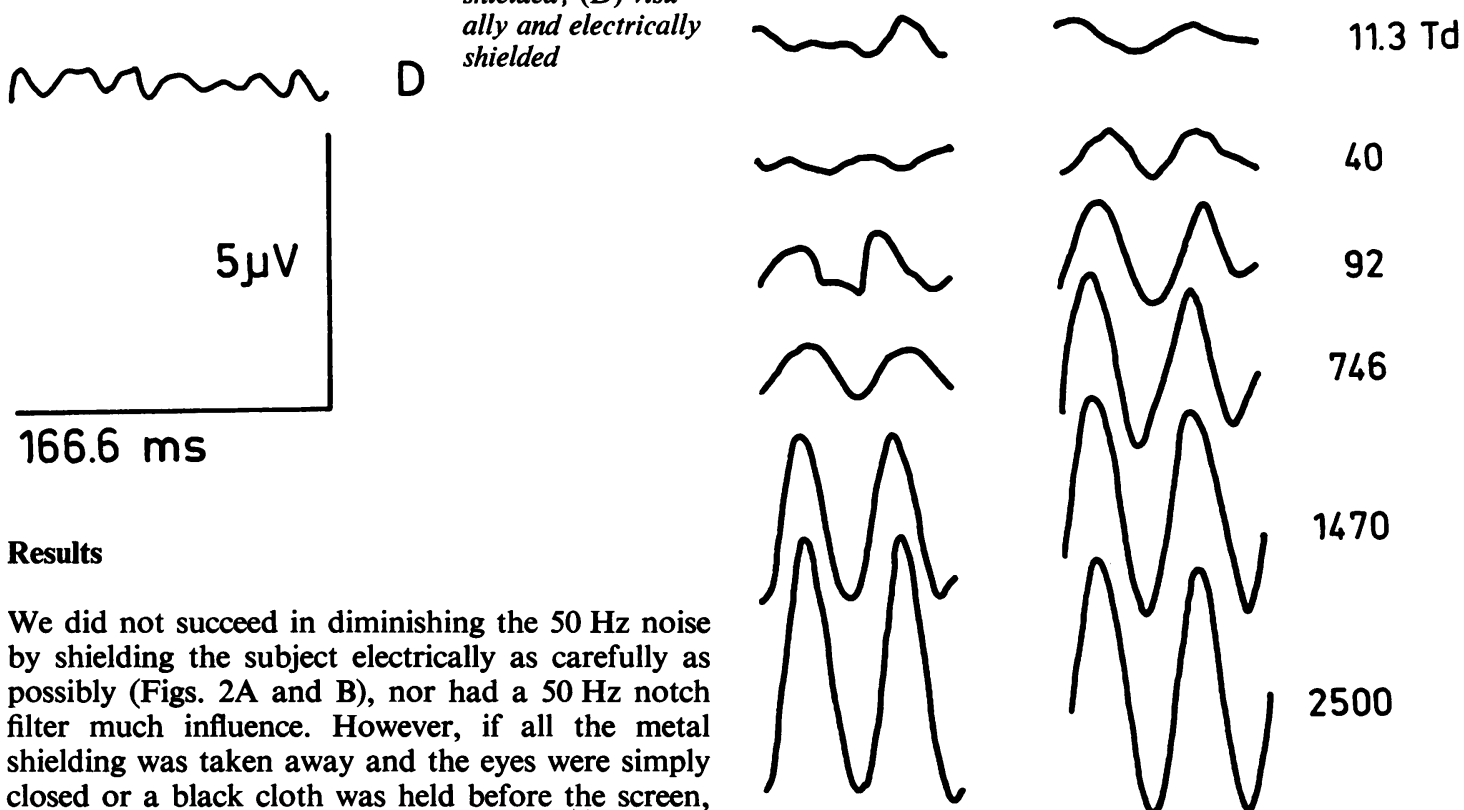

$166.6 \mathrm{~ms}$

\section{Results}

We did not succeed in diminishing the $50 \mathrm{~Hz}$ noise by shielding the subject electrically as carefully as possibly (Figs. 2A and B), nor had a $50 \mathrm{~Hz}$ notch filter much influence. However, if all the metal shielding was taken away and the eyes were simply closed or a black cloth was held before the screen, the $50 \mathrm{~Hz}$ potentials almost entirely vanished (Fig. 2C). Little further improvement was attained when the electrical shields were added. Apparently these potentials were responses mediated through the visual system and not artefacts caused by induction. Further evidence for this inference was obtained by varying the luminance of the screen, which clearly showed the luminance dependence in two subjects (Fig. 3). We called these $50 \mathrm{~Hz}$ potentials 'visual hum'. 
paper by Kelly (1964), which states that the CFF of EPs is just below or over $50 \mathrm{~Hz}$, the result being dependent on retinal illumination. This means that $50 \mathrm{~Hz}$ is a critical frequency, which it also appears to be from the results in our tests. Some of our patients transmit the $50 \mathrm{~Hz}$ to the registering electrode, others do not. Since it is caused by a characteristic of TV systems, visual hum will not be present when projector systems are used.

When using a TV system there are 2 ways to get rid of visual hum, namely, by lowering the mean luminance of the screen, though this will depress the height of the EPs too and will lengthen the latency time, and by increasing the frame frequency of the TV set. The latter solution will also decrease the variability in latency time.

\section{References}

Arden, G. B., and Faulkner, D. J. (1977). A versatile pattern generator for neuro-ophthalmological and paediatric EP and psychophysical tests, using standard television techniques compatible with broadcast colour programmes. In Experimental and Clinical Amblyopia, Proceedings of the XIIIth Iscerg Symposium, Israel, 1975, pp. 165-166. Edited by E. Auerbach. Documenta Ophthalmologica Proceedings Series 11.

Kelly, D. H. (1964). Sine waves and flicker fusion. In Physiology of Flicker, symposium held in Amsterdam, 1963. Proceedings of the 2nd Symposium of the International Society for Clinical Electroretinography, pp. 16-35. Documenta Ophthalmologica, 18. Edited by H. E. Henkes and $\mathbf{L}$. H. van der Tweel.

Lith, G. H. M. van, Marle, G. W. van, and Dok-Mak, G. T. M. van (1978). Variation in latency times of visually evoked cortical potentials. British Journal of Ophthalmology, 62, 220-222. 